\title{
Synthesis of an Integrated Biorefinery via the C-H-O Ternary Diagram
}

\author{
Douglas Han Shin Tay ${ }^{1}$, Houssein Kheireddine ${ }^{2}$, Denny Kok Sum $\mathrm{Ng}^{1}{ }^{*}$ \\ Mahmoud M. El-Halwagi ${ }^{2}$ \\ ${ }^{1}$ Department of Chemical and Environmental Engineering, University of Nottingham \\ (Malaysia Campus), Selangor, Malaysia \\ Denny.Ng@nottingham.edu.my \\ ${ }^{2}$ Artie McFerrin Department of Chemical Engineering, Texas A\&M University, College \\ Station, Texas, USA.
}

An integrated biorefinery is designed to handle a wide variety of feedstocks (mainly biomass) and can produce a broad range of products (e.g., biofuel, biochemicals, etc.) via multiple conversion pathways and technologies. Gasification is recognised as one of the promising options for initial processing of biomass. It uses thermal energy to convert the biomass feedstock into a gaseous mixture, which is also known as syngas, consisting mainly of carbon dioxide $\left(\mathrm{CO}_{2}\right)$, steam $\left(\mathrm{H}_{2} \mathrm{O}\right)$, methane $\left(\mathrm{CH}_{4}\right)$, carbon monoxide $(\mathrm{CO})$ and hydrogen $\left(\mathrm{H}_{2}\right)$. It is noted that the composition of syngas, especially the ratio of $\mathrm{H}_{2}$ to $\mathrm{CO}$, is crucial when the syngas is further converted to liquid fuels and chemicals. In this work, a graphical targeting approach for the evaluation of gas phase equilibrium composition of biomass gasification is proposed. Based on the targeted composition, a conceptual design of an integrated biorefinery can be systematically developed.

\section{Introduction}

Production of biofuels and chemicals derived from biomass is gaining an increasing attention because of its potential in reducing greenhouse emissions. An integrated biorefinery has the capability to process biomass to generate a sustainable supply of biofuels, energy and bulk and fine chemicals (Bridgwater, 2003). In designing costeffective biorefineries, process systems engineering (PSE) approaches can be effective in minimising the consumption of raw materials and energy. An optimum integrated biorefinery is designed to handle a wide variety of feedstock and produce a broad range of products. Gasification is identified as one of the promising options for the initial processing of biomass as it is a robust thermal conversion process. It uses thermal energy to convert the biomass feedstock into a gaseous mixture consisting mainly of carbon dioxide $\left(\mathrm{CO}_{2}\right)$, steam $\left(\mathrm{H}_{2} \mathrm{O}\right)$, methane $\left(\mathrm{CH}_{4}\right)$, carbon monoxide $(\mathrm{CO})$ and hydrogen $\left(\mathrm{H}_{2}\right)$. Such gaseous product is also known as synthesis gas or syngas. It is usable for the generation of heat and power as well as for the production of fuel and other chemicals (e.g., acetic acid, ammonia, methanol, etc.) (Ciferno and Marano, 
2002). In order to optimise the production of syngas for application in an integrated biorefinery, a systematic technique is needed to design the system and predict its performance. In this work, a graphical approach is presented to evaluate equilibrium composition of syngas, optimum operating temperature, and type and amount of oxidants required, based on the syngas requirement of processes to convert syngas into final products (e.g., biofuel, methanol, etc.). These are critical information that constitutes the basis of conceptual design.

\section{C-H-O Ternary Diagram}

The carbon-hydrogen-oxygen (C-H-O) ternary diagram (Cairns and Tevebaugh, 1964) is a useful tool in representing the thermodynamics of thermal processes. Figure 1 shows a C-H-O ternary diagram with three vertices: carbon $(\mathrm{C})$, hydrogen $(\mathrm{H})$ and oxygen $(\mathrm{O})$. A chemical that consists of $\mathrm{C}, \mathrm{H}$ and $\mathrm{O}$ can be represented as a unique point on the C-H-O ternary diagram based on its molar composition. For example, $\mathrm{H}_{2} \mathrm{O}$ is located at $0.66 \mathrm{~mol}$ fraction of $\mathrm{H}$ at the axis of hydrogen-oxygen (H-O).

It is noted that most of the materials involved in biorefinery consist of $\mathrm{C}, \mathrm{H}$ and $\mathrm{O}$. For instance, biomass is normally generalised as $\mathrm{C}_{n} \mathrm{H}_{m} \mathrm{O}_{p}$, where $n, m$ and $p$ are the atomic fraction of $\mathrm{C}, \mathrm{H}$ and $\mathrm{O}$ respectively and those fractions can be determined based on ultimate analysis. Furthermore, other chemical components involved in a biorefinery, such as ethanol $\left(\mathrm{C}_{2} \mathrm{H}_{6} \mathrm{O}\right)$, syngas, water $\left(\mathrm{H}_{2} \mathrm{O}\right)$, carbon dioxide $\left(\mathrm{CO}_{2}\right)$, etc., also consist of $\mathrm{C}, \mathrm{H}$ and $\mathrm{O}$. Therefore, most of these chemicals can be represented within a C-H-O ternary diagram. In addition, in the case where a raw material is converted into products by introducing additional reactants (e.g., oxygen, steam, etc.), the C: $\mathrm{H}$ : $\mathrm{O}$ molar ratios of the products can be located on the C-H-O ternary. Thus, based on the reallocation of points of raw material to products, chemical reaction pathways for a biorefinery can be represented within the C-H-O ternary diagram. Lever-arm rules can be used to illustrate the material balance on a C-H-O ternary diagram. An example to demonstrate the use of lever-arm-rules to determine the amount of oxidants for complete oxidation of biomass using C-H-O ternary diagram is first described. According to Prins et al. (2003), complete oxidation of a biomass, with the formula of $\mathrm{CH}_{1.4} \mathrm{O}_{0.59} \mathrm{~N}_{0.0017}$ is as follows:

$\mathrm{CH}_{1.4} \mathrm{O}_{0.59} \mathrm{~N}_{0.0017}+1.055 \mathrm{O}_{2}+3.99515 \mathrm{~N}_{2} \rightarrow \mathrm{CO}_{2}+0.7 \mathrm{H}_{2} \mathrm{O}+3.996 \mathrm{~N}_{2}$

Since nitrogen $(\mathrm{N})$ does not participate in the reaction and acts as an inert gas, $\mathrm{N}$ is not taken into consideration in the $\mathrm{C}-\mathrm{H}-\mathrm{O}$ representation. Based on the $\mathrm{N}$-free formula of the selected biomass ( $\mathrm{CH} 1.4 \mathrm{O} 0.59)$, the molar ratio of $\mathrm{C}: \mathrm{H}: \mathrm{O}$ is then determined as $0.33: 0.47: 0.20$ and located as the "Biomass" point in Figure 1. To represent the above reaction pathway on the $\mathrm{C}-\mathrm{H}-\mathrm{O}$ ternary diagram, a straight line is first connected between both reactants which are "Biomass" and $\mathrm{O}_{2}$ that located at the vertex labelled 


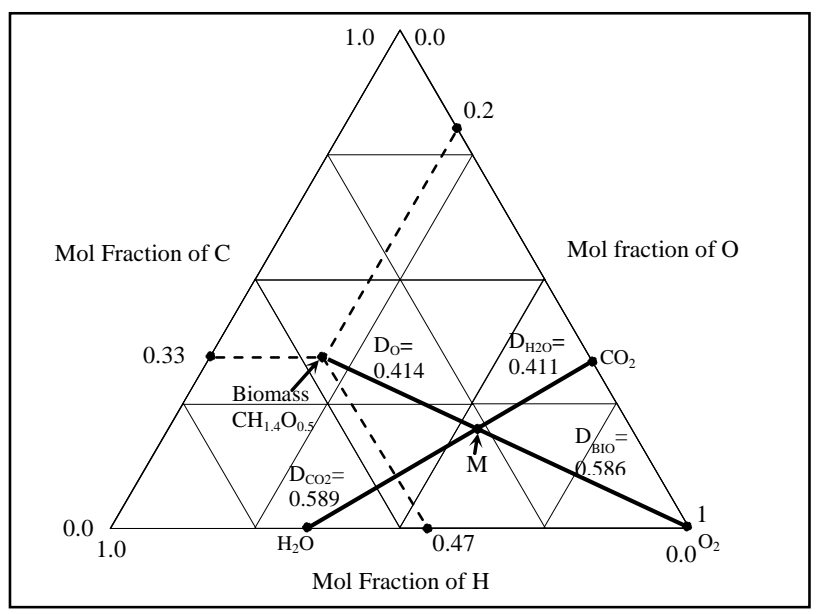

Figure 1: Representation of the oxidation of biomass using the $\mathrm{C}-\mathrm{H}$-O $\mathrm{O}$ ternary diagram

oxygen, O. This line is designated as the reactant line. As shown in Equation 1, the products of complete oxidation are given as $\mathrm{CO}_{2}$ and $\mathrm{H}_{2} \mathrm{O}$, hence, a product line that connects both products is then drawn (refer to Figure 1). Note that the reactant and product lines intersect at the equilibrium point (Point $\mathrm{M}$ ) where the mixture of reactants (biomass and $\left.\mathrm{O}_{2}\right)$ and products $\left(\mathrm{CO}_{2}\right.$ and $\left.\mathrm{H}_{2} \mathrm{O}\right)$ achieve an equilibrium state. If $100 \%$ conversion of biomass is achieved, Point $\mathrm{M}$ will consist purely of the products.

Based on the lever-arm rule, the stoichiometric ratio of biomass: $\mathrm{O}_{2}$ and $\mathrm{CO}_{2}: \mathrm{H}_{2} \mathrm{O}$ can be determined. As shown in Figure 1, the lengths between biomass, $\mathrm{O}_{2}, \mathrm{CO}_{2}$ and $\mathrm{H}_{2} \mathrm{O}$ with mixture $(\mathrm{M})$ are labelled as $\mathrm{D}_{\mathrm{O}}, \mathrm{D}_{\mathrm{BIO}}, \mathrm{D}_{\mathrm{H} 2 \mathrm{O}}$ and $\mathrm{D}_{\mathrm{CO} 2}$, respectively, and given the ratio of $0.414,0.586,0.411$ and 0.589 respectively. Since the $\mathrm{C}-\mathrm{H}-\mathrm{O}$ diagram is originally developed based on atomic mole fractions, the stoichiometric ratios of reactants and products are not directly reflected on the arm lengths. To determine the stoichiometric ratio, the number of atoms in the molecule (reactants and products) is taken into consideration as shown in Equation 2.

$\frac{\text { Length, } \mathrm{D}_{\mathrm{CH}}}{\text { Total length between reactants or products }}=\frac{\text { Stoichiometric coefficien } \mathrm{t} \times \text { Number of atoms in } \mathrm{CH}}{\text { Total number of atoms for all reactants or products }}$

where $\mathrm{CH}$ is referred as a chemical in reactants or products.

For example, since $\mathrm{O}_{2}$ exists as a molecule which consists of two atoms of $\mathrm{O}$, the number of atoms in $\mathrm{CH}$ (in Equation 2) is taken as value of 2. Solving Equation 2 with given value of $\mathrm{D}_{\mathrm{O}}(0.414)$ and a biomass $\left(\mathrm{CH}_{1.4} \mathrm{O}_{0.59}\right)$, the stoichiometric coefficient of oxygen is determined as 1.056. Following a similar approach, the stoichiometric coefficients for $\mathrm{CO}_{2}$ and $\mathrm{H}_{2} \mathrm{O}$ are determined as 1 and 0.7 respectively. It is interesting to note that the stoichiometric coefficients that determined via lever-rule from $\mathrm{C}-\mathrm{H}-\mathrm{O}$ diagram are identical with the oxidation process as presented in Equation 1. During the design, this approach will be useful in a reverse manner. Once a desired point is 
identified on the $\mathrm{C}-\mathrm{H}-\mathrm{O}$ diagram, it is connected to the participating reactants and products, and a stoichiometric expression is derived based on lever-arm rules.

Other than determining the stoichiometric coefficients of reactions, the C-H-O ternary diagram is also applicable to determine the composition of gas-solid equilibrium. Cairns and Tevebaugh (1964) first proposed the use of $\mathrm{C}-\mathrm{H}-\mathrm{O}$ ternary diagram to determine the equilibrium composition of $\mathrm{C}-\mathrm{H}-\mathrm{O}$ systems which consist mainly of $\mathrm{C}, \mathrm{CO}, \mathrm{CO}_{2}, \mathrm{H}_{2}$, $\mathrm{H}_{2} \mathrm{O}$ and $\mathrm{CH}_{4}$. Since the equilibrium state is a function of temperature, different compositions of gaseous mixtures are formed at different operating temperatures. Therefore, the carbon deposition boundaries which consist of $\mathrm{C}, \mathrm{H}$ and $\mathrm{O}$ ratio of the gaseous mixture at equilibrium at different temperatures can be represented on the $\mathrm{C}-\mathrm{H}$ O ternary diagram (Cairns and Tevebaugh, 1964). Note that each point on the carbon deposition boundary line represents a unique equilibrium composition for $\mathrm{H}_{2}, \mathrm{CO}, \mathrm{CO}_{2}$, $\mathrm{H}_{2} \mathrm{O}$ and $\mathrm{CH}_{4}$ and the detail composition can be obtained from tabulated data (Cairns and Tevebaugh, 1964; Baron et al., 1976). As shown by Cairns and Tevebaugh (1964), there is marginally no solid carbon present in the heterogeneous state with the gaseous products on the carbon deposition boundary. According to Cairns and Tevebaugh (1964) and Baron et al. (1976), the equilibrium composition calculated for a C-H-O system is valid for gasification, waste conversion, and combustion of carbonaceous fuels, steam methane reforming and fuel cells. Although the equilibrium state is rarely attained in a gasification process, determining the maximum conversion limits that are set by equilibrium is an important target.

\section{Synthesis of an Integrated Biorefinery via the C-H-O Ternary Diagram}

As presented previously, biomass gasification is normally used as a first processing step in an integrated biorefinery. Thus, syngas composition from gasification is a crucial parameter to allow the syngas to be further converted to valuable products via chemical synthesis processes (e.g., Fischer-Tropsch, methanol synthesis, etc.). Since the equilibrium composition of syngas is strongly affected by the type of biomass, type and amount of oxidants (e.g., steam and $\mathrm{O}_{2}$ ) as well as gasification temperature, thus, selecting the optimum parameters is crucial. Based on the insight of C-H-O ternary diagram, it is adapted for synthesis of an integrated biorefinery in this work. To illustrate the details of the synthesis approach via the C-H-O ternary diagram, a simplified case study of a biorefinery is discussed in next section.

\section{Case Study}

In this case study, given is a feedstock of corncob to produce methanol in an integrated biorefinery. First, corncob is gasified into syngas via gasification system that operates at $1500 \mathrm{~K}$ and $1 \mathrm{~atm}$. Next, the syngas is further converted into methanol via methanol synthesis process. According to Ciferno and Marano (2002), the syngas composition required for methanol synthesis is $\mathrm{H}_{2} / \mathrm{CO} \geq 2$ and $\mathrm{CO}_{2} / \mathrm{CO} \leq 0.6$. As shown in Figure 2, when a gasifier operates at $1500 \mathrm{~K}$, the syngas composition is mainly dominated by $\mathrm{H}_{2}$ and $\mathrm{CO}$ (a straight line between $\mathrm{CO}$ and the $\mathrm{H}$ vertex). Therefore, the equilibrium point of gasification is located on the carbon deposition boundary at $1500 \mathrm{~K}$. Following the 
approach presented in the previous section, the lever-arm rule can be used to determine the stoichiometric coefficients and equilibrium composition of syngas. Since two oxidants (steam and oxygen) are available for gasification, both alternatives are analysed based on the $\mathrm{C}-\mathrm{H}-\mathrm{O}$ ternary diagram. As shown in Figure 2, two straight lines are connected between $\mathrm{H}_{2} \mathrm{O}$ and $\mathrm{O}_{2}$ with corncob, forming two equilibrium points with the product line (carbon deposition boundary at $1500 \mathrm{~K}$ ). Based on the requirement of methanol synthesis process $\left(\mathrm{H}_{2} / \mathrm{CO} \geq 2\right)$, a desired product point (Point $\mathrm{S}$ ) is located in Figure 2. To achieve the desired syngas composition, equilibrium point on or closest to Point $S$ is preferable. It is noted that the equilibrium point of steam gasification is closer to Point $\mathrm{S}$; hence, steam is selected as the oxidant in this process. As the syngas composition from corncob steam gasification alone does not fulfil the process requirement (Point $\mathrm{S}$ ), additional $\mathrm{H}_{2}$ is required to shift the equilibrium point closer to Point S. In this case, steam methane reforming (SMR) is selected as it produces syngas with high $\mathrm{H}_{2}$ composition. Following a similar approach, the equilibrium point of SMR can be determined by connecting methane $\left(\mathrm{CH}_{4}\right)$ and $\mathrm{H}_{2} \mathrm{O}$ (as shown in Figure 2).

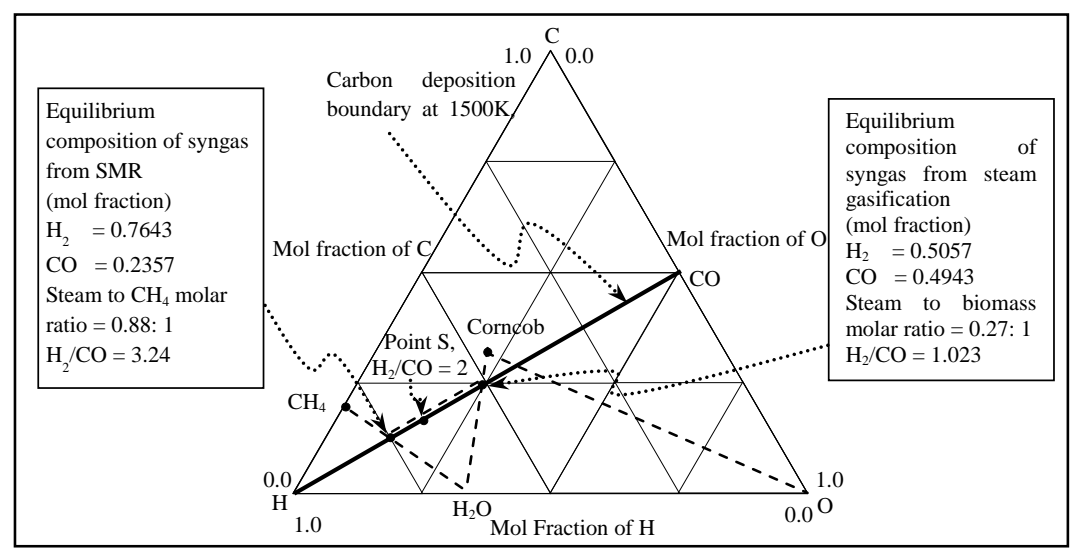

Figure 2: C-H-O ternary diagram with carbon deposition boundary at $1500 \mathrm{~K}, 1 \mathrm{~atm}$. (Cairns and Tevebaugh, 1964)

Note that Point $\mathrm{S}$ is located between the equilibrium points of SMR and biomass gasification. Hence, the desired syngas composition for methanol synthesis can be obtained by mixing syngas from both processes. Based on the approach presented in the previous section, the optimum steam to biomass ratio and SMR to corncob steam gasification ratio can be determined via lever-arm rule. Based on Figure 2 and Equation 2 , the optimum steam to biomass ratio is determined as $0.27: 1.00$. Meanwhile, the optimum mixture ratio of syngas from SMR and corncob steam gasification is calculated as 1.000:0.613 (SMR: Corncobs steam gasification). Note that based on the insight of C-H-O ternary diagram, a conceptual design of an integrated biorefinery can be synthesized. 


\section{Conclusion}

In this work, an insight-based synthesis tool of carbon-hydrogen-oxygen (C-H-O) ternary diagram is presented for the conceptual design of an integrated biorefinery. Based on the insights of the $\mathrm{C}-\mathrm{H}-\mathrm{O}$ ternary diagram, the equilibrium composition and optimum operating parameters of biomass gasification can be determined. In addition, the $\mathrm{C}-\mathrm{H}-\mathrm{O}$ ternary diagram is also used to provide a quick targeting tool that aids in the evaluation and analysis of alternatives. Further works to incorporate the C-H-O ternary diagram as part of a systematic synthesis framework for an integrated biorefinery is to be developed.

\section{Acknowledgement}

The financial support from University of Nottingham Research Committee through New Researcher Fund (NRF 5021/A2RL32) is gratefully acknowledged.

\section{References}

Bridgwater A.V., 2003, Renewable fuels and chemicals by thermal processing of biomass, Chem. Eng. J., 91, 87-102.

Baron R.E., Porter J.H and Hammond Jr. O.H., 1976, Chemical Equilibria in CarbonHydrogen-Oxygen Systems. MIT Press, Massachussetts, USA.

Cairns E.J. and Tevebaugh A.D., 1964, CHO gas phase compositions in equilibrium with carbon and carbon deposition boundaries at one atmosphere, J. Chem. Eng. Data, 9(3), 453-462.

Ciferno J.P. and Marano J.J., 2002, Benchmarking Biomass Gasification Technologies for Fuels, Chemicals and Hydrogen Production. US Department of Energy, <www.netl.doe.gov/coal/gasification/pubs/pdf/BMassGasFinal.pdf>, (last accessed 14.05.2010).

Prins M.J., Ptasinski K.J. and Janssen F.J.J.G., 2003, Thermodynamics of gas-char reactions: first and second law analysis, Chem. Eng. Sci., 58, 1003-1011. 